ORIGINAL ARTICLE

\title{
An occupational health intervention programme for workers at risk for early retirement; a randomised controlled trial
}

\author{
A G E M de Boer, J-C van Beek, J Durinck, J H A M Verbeek, F J H van Dijk
}

Occup Environ Med 2004;61:924-929. doi: 10.1136/oem.2003.009746

See end of article for authors' affiliations .....................

Correspondence to: Dr A GE M de Boer, Coronel Institute for Occupational and Environmental Health Academic Medical Center, PO Box 22660, 1100 DD Amsterdam, Netherlands; a.g.deboer@amc.uva.n

Accepted 10 May 2004
Aims: To evaluate an occupational health intervention programme for workers at risk for early retirement. Methods: Between April 1997 and May 1998, 116 employees of a large company who were older than 50 years indicated that they would not be able to work up to their retirement. They were randomly assigned to an intervention $(n=61)$ or control group $(n=55)$. The intervention programme lasted six months and was executed by an occupational physician. Job position and number of sick leave days after two years were collected from the company's computer database. A questionnaire was sent to the employees at baseline, after six months, and after two years; it included the Work Ability Index, the Utrecht Burn Out Scale, and the Nottingham Health Profile measuring quality of life.

Results: Fewer employees (11\%) in the intervention group retired early than in the control group (28\%). The total average number of sick leave days in two years was 82.3 for the intervention group and 107.8 for the control group. Six months after baseline, employees in the intervention group had better work ability, less burnout, and better quality of life than employees in the control group. Two years after randomisation no differences between the two groups were found.

Conclusions: This occupational health intervention programme proved to be a promising intervention in the prevention of early retirement. p many countries throughout the industrialised world the population is ageing; this is largely caused by the increasing life expectancy. As an economic result, public costs for pensions and healthcare are increasing and will continue to do so in the near future. Consequently, workers may need to work longer and retire later than they have done in recent years. ${ }^{1}$ Prevention of early retirement will therefore become even more important.

The prolongation of working life should be accomplished without threatening the wellbeing of elderly persons. Interventions on either societal, organisational, and/or individual levels could help to prevent aged workers from early retirement while work ability, (mental) health, and quality of life are maintained. However, no scientific evidence based intervention studies have as yet been conducted on interventions preventing early retirement from working life. ${ }^{2}$

Previous studies have found several factors to be predictive of early retirement or not returning to work after prolonged sick leave. Sociodemographic factors found to be associated with early retirement were: older age, ${ }^{23}$ lower education, ${ }^{4}$ and having a partner. ${ }^{5}$ Health related factors frequently found to be associated with early exits from work were: poor health, ${ }^{367}$ chronic complaints, ${ }^{4}$ and poor medical work capacity. ${ }^{8}$ Work related factors such as negative attitude towards work, ${ }^{6}$ less satisfaction with the job, ${ }^{2}{ }^{7}$ and adverse work conditions such as extreme bending of the back ${ }^{5}$ also influenced the employees' decisions to retire early. Additionally, the expected loss of income after retirement, ${ }^{6}$ longer working life ( $>35$ years), ${ }^{7}$ and being among the higher paid employment grades, ${ }^{7}$ were associated with early retirement.

It was hypothesised that active age management and coaching of the individual older employee with difficulties prolonging his or her working life could prevent the ageing worker from early retirement ${ }^{9}$ by improving the work ability and quality of life. ${ }^{10-12}$ Therefore, an intervention programme was constructed based on the predictors of early retirement found in the literature. The occupational health intervention programme started with the identification of individual predictors for early retirement focusing on health factors, work related factors, and social/psychological factors. A management plan was then set up in which solutions should be found, and executed by the occupational physician, in collaboration with the employee's supervisors and personnel managers and with possible referral to general practitioners, medical specialists, and psychologists.

The aim of this study was to evaluate if this occupational health intervention programme for workers at risk could reduce early retirement and increase the work ability, reduce stress related symptoms, and improve quality of life and satisfaction with the occupational physician's care.

\section{METHODS}

\section{Subjects}

All subjects in this study were employees of a large international company, which develops and manufactures electronic equipment. The main factories are located in the south of the Netherlands, where approximately 10000 employees work. All subjects were 50 years of age or older.

\section{Design}

Between April 1997 and May 1998, all approximately 2000 employees of the company who were older than 50 years and working in the south of the Netherlands, were routinely invited by their occupational physician for their periodical health check-up for the ageing workers. The check-up is voluntary and takes place every two years. All employees were provided with written information (leaflet) about the present study before the start of the examination.

Part of the procedure was a questionnaire on medical, occupational, and psychological topics. One of the questions stated: "Can you maintain your job until your retiring date?" Of the approximately 1450 older employees who participated in the check-up, $160(11 \%)$ indicated that they would not be able to work up to their retirement. An assistant asked those 160 persons whether they wanted to participate in the study. 
Main messages

- Workers in developed countries may need to work longer and retire later.

- In this study, 116 employees at risk of early retirement were randomised into an occupational health intervention programme or care as usual.

- Fewer employees in the intervention group retired early.

- Directly after the intervention employees in the intervention group had better work ability, less burnout, and better quality of life. One and a half years later, these differences had faded.

If they gave informed consent, the assistant would randomly assign the employee to the intervention or control group. The employees in the intervention group were offered the occupational health intervention programme and employees in the control group were offered care as usual. At baseline, six months and two years after randomisation, a questionnaire was sent to all employees in the study to measure outcomes.

\section{Intervention versus care as usual}

The occupational health programme for older workers at risk for early retirement was executed by the worker's own occupational physician. Fifteen occupational physicians were involved in the study.

The programme comprised at least three consultations including an assessment interview. The procedure included the construction of a detailed action plan, consultation of the employee's supervisors and personnel managers, and, if appropriate, referral to the general practitioner, a medical specialist, or psychologist. In the assessment interview, the occupational physician explored the reasons of the employee not being capable to work up to the pension date, concentrating on health factors, work related factors, and social/psychological factors. The action plan focused on aspects that should be changed and necessary adaptations, in order to enable the employee to remain working. Then the occupational physician conferred with the employee's supervisors and personnel managers, general practitioner, medical specialist, or psychologist. Two more scheduled consultations with the occupational physician took place 10 and 16 weeks after the initial interview, in addition to consultations on request. The occupational physicians were trained by the principal researcher (JCvB) by means of a structured protocol. Individual feedback was given during the intervention. The intervention ended six months after the assessment interview.

To assess the process variables of the intervention, a personal file was written by the occupational physician for each employee in the intervention group. The file included: number of visits to the occupational physician in the six months of the intervention, main problem of the employee, type of problem (health related, work related, or social/ psychological), and main action of the occupational physician: contact with the personnel service in order to alter the work conditions, including changes in work tasks, extra tools and aids, other working hours, and improvement in work relations; "wait and see"; start psychosocial counselling with the employee; or refer the employee to another physician.

The employees in the control group received care as usual: they were not invited for a consultation but they could always consult their occupational physician on request.

\section{Policy implications}

- An occupational health intervention programme should be provided to workers at risk of early retirement.

\section{Measurements}

Data on age, sex, years in the company, years until regular retirement age, and salary group (higher or lower) were collected at baseline from the company's computer database. At baseline, data were gathered about marital status (single, married, divorced, widower) and education level (lower, high school, university).

Primary endpoint was early retirement, which was defined as retirement before the agreed pension date, which was assessed individually per employee at $60-65$ years of age. A secondary endpoint was defined as disability pension, since ageing workers could also leave the workforce due to health problems and therefore could be granted a disability pension. Early pensions provide less income than disability pensions, because the latter give $100 \%$ of the last salary for two years and $70 \%$ thereafter. Early pensions immediately drop to $70 \%$.

Two years after the start of the intervention, data on the present occupation were collected from the company's computer database. The data were categorised as early retirement, same work in same company, other work in same company, other work in other company, regular pension, partly working/partly disability pension, or disability pension.

Other secondary endpoints were work ability, stress related symptoms, quality of life, sick leave, and satisfaction with the occupational physician's care. Work ability was assessed with the Work Ability Index (WAI), ${ }^{13}$ which covers seven items, each of which is evaluated with the use of one or more questions. The WAI is a reliable ${ }^{14}$ and valid ${ }^{15}$ standardised measure of work ability. Scores range from 7 to 49 ; higher scores indicate better work ability. Stress related symptoms were measured with the Utrechtse Burn-out Scale (UBOS), which is the Dutch version of the Maslach Burnout Inventory (MBI). The UBOS consists of three subscales: emotional exhaustion (five items), mental distance (five items), and competence (six items). Higher scores on exhaustion and distance and lower scores on competence indicate burnout. The UBOS is a reliable and valid instrument. ${ }^{16}$ Quality of life was measured with the Nottingham Health Profile (NHP), which is a reliable and valid standardised measure of quality of life. ${ }^{17}$ The instrument contains 38 items measuring energy (three items), pain (eight items), emotional reactions (nine items), sleep (five items), social isolation (five items), and physical mobility (eight items). The NHP is scored on a yes/no scale. All raw scales were linearly converted to a 0-100 scale, with higher scores indicating more problems and lower levels of quality of life. The WAI, UBOS, and NHP were measured at baseline, after six months, and after two years.

From the company's computer database on sick leave data, the number of sick leave days were collected at six months, 12 months, and two years after baseline for the employees still working for the company.

In the intervention group, satisfaction with the occupational physician's care in the intervention was measured with 18 questions (for example, the occupational physician has enough time for me), ranging from 1 (totally agree) to 5 (totally disagree). These data were collected directly after the intervention at six months from baseline.

\section{Statistical analysis}

All data were checked and analysed using the Statistical Package for the Social Sciences (SPSS-10.0). All data were 
analysed on an intention-to-treat analysis, based on the groups as randomised.

Descriptive data were determined for the baseline characteristics. Differences in baseline characteristics were tested with $t$ tests for continuous data and $\chi^{2}$ tests for ordinal data. Differences between the two groups in occupation after two years were tested with $\chi^{2}$ tests. Repeated measurement analyses were used to test for the effect of the intervention on work ability, burnout, and quality of life at baseline and six months' follow up, at baseline, and at two years' follow up, respectively. To take possible differences in pre-test scores into account, interaction effects of groups by time are reported.

Because the data on sick leave days were skewed, the Mann-Whitney U test was used to test for differences in sick leave days at six months, one year, and two years after baseline.

Descriptive data were determined for satisfaction with the intervention and for process variables.

Analysis of variance was used to test the scores at six months between the employees who either did or did not complete the last questionnaire at two years and to test for interaction effects of intervention group by non-response at two years, in order to investigate whether subjects with low results at six months have dropped out of the project at two years.

Probability values $<0.05$ (two sided) were considered statistically significant.

\section{RESULTS}

\section{Subjects}

Of the 160 employees asked to participate in this study, 116 (73\%) agreed and returned the baseline questionnaire. Forty patients gave no informed consent and four patients did not return the baseline questionnaire. Of these 116 employees, 61 were randomised into the intervention group and 55 were randomised into the control group. Table 1 presents baseline characteristics. The average age was 53.4 years (SD 2.2; range 50-58) and $93 \%$ of the subjects were male. The low rate of women in the study group is comparable with the rate in the overall group of 1450 older workers. On average, employees had been working approximately 30 years for the company and should continue to work for another 8.5 years until their regular pension. The average agreed regular pension age was

Table 1 Baseline characteristics for the intervention and control groups

\begin{tabular}{|c|c|c|c|}
\hline & $\begin{array}{l}\text { Intervention } \\
(n=61) \\
n(\%)\end{array}$ & $\begin{array}{l}\text { Control } \\
\text { (n=55) } \\
n(\%)\end{array}$ & $\mathbf{p}^{*}$ \\
\hline Age, mean $(y)$ & 53.2 & 53.5 & NS \\
\hline Sex (male) & $58(95 \%)$ & $50(91 \%)$ & NS \\
\hline \multicolumn{4}{|l|}{ Education† } \\
\hline Lower & $27(48 \%)$ & $22(46 \%)$ & \multirow[t]{3}{*}{ NS } \\
\hline High school & $12(21 \%)$ & $13(27 \%)$ & \\
\hline College/university & $17(30 \%)$ & $13(27 \%)$ & \\
\hline \multicolumn{4}{|l|}{ Marital status $\dagger$} \\
\hline Single & $5(9 \%)$ & $3(6 \%)$ & \multirow[t]{4}{*}{ NS } \\
\hline Married/cohabiting & $48(86 \%)$ & $41(85 \%)$ & \\
\hline Divorced & $3(6 \%)$ & $2(4 \%)$ & \\
\hline Widower & $0(0 \%)$ & $2(4 \%)$ & \\
\hline Employment grade (low)† & $34(61 \%)$ & $34(71 \%)$ & NS \\
\hline $\begin{array}{l}\text { Years working for company, } \\
\text { mean }(y)\end{array}$ & 29.1 & 30.2 & NS \\
\hline $\begin{array}{l}\text { Years until regular pension, } \\
\text { mean }(y)\end{array}$ & 8.4 & 8.6 & NS \\
\hline Regular pension age, mean $(y)$ & 61.6 & 62.1 & NS \\
\hline
\end{tabular}

61.8 years. No differences in baseline characteristics between the two groups were found.

\section{Intervention}

A personal file was written by the occupational physician for 53 of the 61 employees in the intervention group with data on the intervention. The average number of visits to the occupational physician in the six months of the intervention was 2.6 (range 0-9, SD 1.6). The most common reasons for the employees not being able to work up to retirement were work related $(87 \%)$, while health related $(10 \%)$ and social related reasons $(3 \%)$ were less common. The majority of the employees $(57 \%)$ indicated that work demands or work stress was the main problem. Other problems were conflicts with their supervisors $(11 \%)$, too little or dull work $(8 \%)$, and musculoskeletal complaints $(6 \%)$.

The occupational physician sought contact with the employee's supervisors and personnel managers in $72 \%$ of the cases. In $52 \%$ of the cases, he/she contacted the personnel service in order to alter the work conditions, including changes in work tasks, extra tools and aids, other working hours, and improvement in work relations. In other cases, the occupational physician would "wait and see" (15\%), start psychosocial counselling with the employee $(11 \%)$, or refer the employee to another physician (4\%).

\section{Occupation two years after baseline}

Two years after the start of the intervention programme, data were available for 100 employees on their current work situation, as is shown in table 2 . In the intervention group, six employees $(11 \%)$ had retired early, which is significantly less $(p=0.04)$ than in the control group in which $13(28 \%)$ employees chose early retirement. When the data of employees leaving on early retirement or disability pension were combined, results showed that $9(17 \%)$ employees in the intervention group and $13(28 \%)$ in the control group left on early retirement or disability pension $(p=0.20)$. In addition, 44 employees $(83 \%)$ in the intervention group were still working or went into regular pension versus 34 employees $(72 \%)$ in the control group $(p=0.20)$.

\section{Work ability, burnout, and quality of life}

At baseline, 116 questionnaires were returned. Six months after randomisation at the end of the intervention programme, 61 questionnaires were returned in the intervention group (100\%) and $52(95 \%)$ in the control group. Two years after the randomisation, 40 employees $(66 \%)$ in the intervention group returned the questionnaire, compared to 34 $(62 \%)$ employees in the control group.

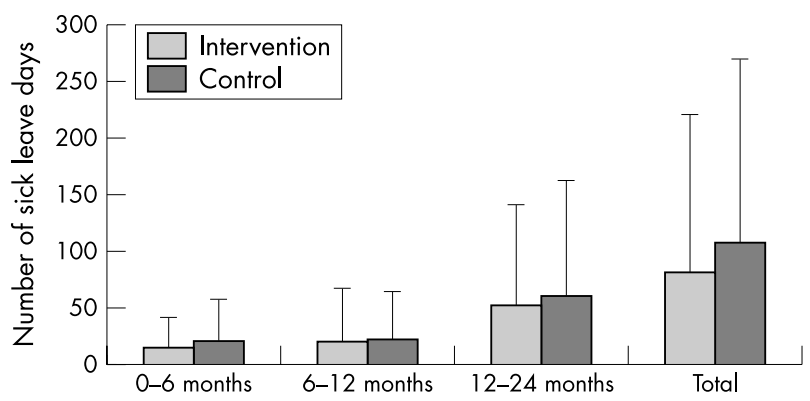

Figure 1 Average number of sick leave days in the first 6 months, 6-12 months, in the second year, and total number of sick leave days for the intervention group and the control group. Standard deviations are indicated above the bars; number of subjects at each measurement: 6 months ( $n=48$ intervention subjects and $n=44$ controls), 6-12 months $(n=40$ and $n=31), 12-24$ months $(n=40$ and $n=31)$, and total $(n=40$ and $n=31$ ). 


\begin{tabular}{|c|c|c|c|}
\hline Work situation after two years & $\begin{array}{l}\text { Intervention } \\
\mathbf{n}(\%)\end{array}$ & $\begin{array}{l}\text { Control } \\
\text { n (\%) }\end{array}$ & $\mathbf{p}^{*}$ \\
\hline Early retirement & $6(11 \%)$ & $13(28 \%)$ & 0.04 \\
\hline Disability pension & $3(6 \%)$ & $0(0 \%)$ & NS \\
\hline Regular pension & $2(4 \%)$ & $0(0 \%)$ & NS \\
\hline \multicolumn{4}{|l|}{ Still working: } \\
\hline Same work in same company & $38(72 \%)$ & $30(64 \%)$ & NS \\
\hline Other work in same company & $0(0 \%)$ & $2(4 \%)$ & NS \\
\hline Other work in other company & $2(4 \%)$ & $2(4 \%)$ & NS \\
\hline Partly working/partly disability pension & $2(4 \%)$ & $0(0 \%)$ & NS \\
\hline Total & $53(100 \%)$ & $47(100 \%)$ & \\
\hline
\end{tabular}

Table 3 shows the scores of both groups for work ability, burnout, and quality of life. At baseline the intervention group showed significantly worse emotional wellbeing and social isolation than the control group. No other differences between the groups were found at baseline.

Six months after baseline, results of the repeated measures analysis indicated that the employees in the intervention group had statistically significant better work ability, less burnout, and better quality of life than employees in the control group. Specifically, the employees in the intervention group showed less emotional exhaustion, emotional distance, had more energy, slept better, and had better emotional wellbeing than the employees in the control group.

Two years after randomisation which is one and a half years after the end of the intervention programme, results of the repeated measurement analysis showed no significant differences in the scores on work ability, burnout, and quality of life between the two groups, except for less emotional distance on the burnout scale for the employees in the intervention group.

Non-response tests comparing the scores at six months between the employees who either did or did not complete the last questionnaire at two years, showed that there were no differences between the groups at six months, except for worse work ability in the non-response group. Moreover, the (non) response rates were similar in both groups, and additional tests showed that there was no interaction effect of intervention group by nonresponse.

\section{Sick leave days}

Data on the number of sick leave days in the first six months were available for 48 employees in the intervention group and 44 employees in the control group. For one year and two years after baseline data were only available for employees still working at the company which were 40 in the intervention group and 31 in the control group. Figure 1 presents number of sick leave days in the first six months, next six months, in the second year, and total number of sick leave days for both groups. None of the differences in sick leave days were statistically significant. During the intervention programme in the first six months after randomisation, the average number of sick leave days was 15.4 days in the intervention group and 21.4 days in the control group (Mann-Whitney $\mathrm{U}=905, \mathrm{p}=0.23$ ). The total average number of sick leave days in the two years after randomisation was 82.3 for the employees in the intervention group and 107.8 for the employees in the control group (Mann-Whitney $\mathrm{U}=557, \mathrm{p}=0.47)$.

\section{Satisfaction with the occupational physician's care}

All 61 employees in the experimental group provided information about their satisfaction with the consultations with the occupational physician during the six months of the intervention. Seventy nine per cent of the employees were (very) satisfied with the occupational physician's consultations. Most positive aspects of the 15 occupational physicians were friendliness (90\% (totally) agreed), trustfulness (90\%), taking enough time for the employee $(88 \%)$, and listening well $(87 \%)$. Least satisfaction was reported for arranging

Table 3 Work ability, burnout, and quality of life of the intervention group and the control group at baseline, six months after randomisation, and two years after randomisation

\begin{tabular}{|c|c|c|c|c|c|c|c|c|c|}
\hline & \multicolumn{3}{|l|}{ Baseline } & \multicolumn{3}{|l|}{ Six months } & \multicolumn{3}{|l|}{ Two years } \\
\hline & $\begin{array}{l}\text { Intervention } \\
(\mathrm{n}=61)\end{array}$ & $\begin{array}{l}\text { Control } \\
(n=55)\end{array}$ & $\mathbf{p}$ & $\begin{array}{l}\text { Intervention } \\
(\mathrm{n}=61)\end{array}$ & $\begin{array}{l}\text { Control } \\
(n=52)\end{array}$ & $\mathbf{p}$ & $\begin{array}{l}\text { Intervention } \\
(n=40)\end{array}$ & $\begin{array}{l}\text { Control } \\
(n=34)\end{array}$ & $\mathbf{p}$ \\
\hline \multicolumn{9}{|l|}{ Burnout (UBOS) } & NS \\
\hline Exhaustion $\dagger$ & 2.7 & 2.6 & NS & 2.4 & 2.7 & $<0.05$ & 2.2 & 2.2 & NS \\
\hline Distance $†$ & 2.7 & 2.3 & NS & 2.5 & 2.7 & $<0.01$ & 2.1 & 2.5 & $<0.05$ \\
\hline Competenceł & 4.0 & 4.1 & NS & 4.0 & 3.9 & NS & 4.0 & 4.0 & NS \\
\hline \multicolumn{10}{|l|}{ Quality of life (NHP)§ } \\
\hline Energy & 34.4 & 30.9 & NS & 26.2 & 37.8 & $<0.01$ & 23.0 & 31.4 & NS \\
\hline Pain & 15.8 & 14.5 & NS & 16.6 & 14.4 & NS & 18.4 & 15.8 & NS \\
\hline Emotional & 30.8 & 23.2 & $<0.05$ & 21.7 & 32.3 & $<0.001$ & 16.9 & 18.3 & NS \\
\hline Sleep & 30.5 & 30.5 & NS & 27.5 & 37.3 & $<0.05$ & 20.5 & 32.4 & NS \\
\hline Social isolation & 11.8 & 6.5 & $<0.05$ & 8.5 & 9.2 & NS & 8.0 & 3.5 & NS \\
\hline Physical mobility & 10.2 & 8.6 & NS & 11.9 & 10.6 & NS & 13.1 & 10.3 & NS \\
\hline $\begin{array}{l}\text { *Higher scores mean } \\
\text { †Higher scores indica } \\
\text { †Lower scores indicat } \\
\text { §Lower scores indicate }\end{array}$ & $\begin{array}{l}\text { ability. } \\
\text { rnout. } \\
\text { nout. } \\
\text { ality of life. }\end{array}$ & & & & & & & & \\
\hline
\end{tabular}


good work adjustments (49\% agreed), preventing worrying $(65 \%)$, and giving good advice $(67 \%)$.

\section{DISCUSSION}

The aim of this study was to evaluate an occupational health intervention programme for workers at risk for early retirement in a randomised controlled trial. Two years after the start of the programme, fewer employees in the intervention group had retired early than in the control group. However, both groups were as successful at remaining to work or having a regular pension. Immediately after the intervention, workers in the experimental group had statistically significant better work ability, less burnout, and better quality of life than employees in the control group. However, two years after randomisation, no significant differences between the two groups could be found. Although the employees in the intervention group were sick listed less often, this difference was not statistically significant.

Interventions, be it on societal, organisational, or individual level, need to be supported by evidence obtained through research. ${ }^{2}$ This study is the first published randomised trial on prevention of early retirement. A multidisciplinary approach was applied and the effect of the intervention on several outcome measures was investigated. The intervention programme appeared to be well organised and executed. As planned, the employees had approximately three consultations with the occupational physician and contact with the employee's supervisors or personnel managers was sought in the majority of the cases. Usually, a personal action plan file was written. In addition, this study shows that it is feasible to execute a randomised study on occupational health management of older workers. Although subjects in the intervention and control group worked for the same company, only 116 of the 10000 workers were included in this study. Therefore, the chances that the subjects in the intervention and control group would have interacted, are relatively small.

One problem in the study was the relatively small group and the loss to follow up after two years. Although the project started with a very large group of approximately 2000 employees, the final study group comprised 116 persons. As a result, some interesting differences between the two groups, such as the number of sick leave days, might clearly be relevant for employees and companies, but were not statistically significant. At the last measurement information on work ability, burnout, and quality of life was available on only 40 employees $(66 \%)$ in the intervention group and 34 $(62 \%)$ employees in the control group. This loss to follow up could be caused by the fact that the intervention had finished a long time previously, and therefore some employees might not have felt related to the study anymore. Some employees had retired or left the company and might therefore not have returned the questionnaire. Alternatively, it is possible that the employees lost to follow up were those having worse work ability, burnout, or quality of life. However, the nonresponse rates were similar in both groups, and non-response tests showed that non-response would not have influenced the burnout or quality of life results between the intervention and control groups. The non-respondents did score worse, however, on work ability at six months.

Contrary to expectations, the majority of the reasons for planning early retirement were work related and not health related. Earlier research indicated that both health related factors ${ }^{3}{ }^{4}{ }^{7}$ and work related factors ${ }^{2}{ }^{6}$ were frequently found to be associated with early exits from work. It might be possible that other studies focused on the employees who actually retired early, which is often caused by an acute or chronic illness. This study focused on workers at risk for early retirement, of which the majority remained in the company.
This seems to be another group that is mainly bothered by work related problems.

Two years after the start of the programme, fewer employees in the intervention group had retired early than in the control group. However, some employees in the intervention group were receiving disability pensions and as a result, no significant differences were found in the total percentage of employees still working or receiving regular pensions after two years ( $83 \%$ versus $72 \%$ ). It is possible that the medical attention in the intervention programme has brought about a shift from early retirement to medical retirement and therefore more workers in the intervention group received a disability pension. However, the results on the questionnaires measuring burnout and quality of life showed that at least in the beginning of the intervention period the workers in the intervention group experienced beneficial effects.

The majority of the employees in the intervention group were (very) satisfied with the occupational physician's care. Employees were most satisfied with communication skills such as friendliness, trustfulness, taking enough time for the employee, and listening well, while least satisfaction was reported for arranging good work adjustments, preventing worrying, and giving good advice. Work related problems were most dominant in this study, and therefore the focus of the intervention was predominately on workplace changes. However, subjects were the least satisfied about this aspect. It might have been the case that the expectations of the employees regarding the direct influence of the occupational physician on their work conditions were too high or that the changes took longer to take effect than anticipated. Future research should investigate this aspect in more detail.

This occupational health intervention programme for workers at risk for early retirement proved to be a promising intervention, because less employees in the intervention group retired early and they showed better work ability, less burnout, and better quality of life directly after the programme. An intervention programme that runs longer could be more effective, because some effects seem to fade after the end of the programme. Future research should study a large group of employees and put more emphasis on work related factors.

\section{Authors' affiliations}

A G E M de Boer, J H A M Verbeek, F J H van Dijk, Coronel Institute for Occupational and Environmental Health, Academic Medical Center, University of Amsterdam, Netherlands

J-C van Beek, Medicum Consult, Organisation for Occupational Medicine, Valkenswaard, Netherlands (formerly Arbo Management Group, Eindhoven, Netherlands)

J Durinck, Arbo Management Group, Eindhoven, Netherlands

\section{REFERENCES}

1 Griffiths A. Designing and managing healthy work for older workers. Occup Med (Lond) 2000;50:473-7.

2 Kilbom A. Evidence-based programs for the prevention of early exit from work. Exp Aging Res 1999;25:291-9.

3 Taylor MA, Shore LM. Predictors of planned retirement age: an application of Beehr's model. Psychol Aging 1995; 10:76-83.

4 Siddiqui S. The impact of health on retirement behaviour: empirical evidence from West Germany. Health Econ 1997;6:425-38.

5 Lund T, Iversen L, Poulsen KB. Work environment factors, health, lifestyle and marital status as predictors of job change and early retirement in physically heavy occupations. Am J Ind Med 2001;40:161-9.

6 Henkens K. [Who wants to go in early retirement? A multivariate analysis of civil servants' intention to retire early or not]. Tijdschr Gerontol Geriatr 1993;24:129-36

7 Mein G, Martikainen P, Stansfeld SA, et al. Predictors of early retirement in British civil servants. Age Ageing 2000;29:529-36.

8 Astrand NE, Isacsson SO, Olhagen GO. Prediction of early retirement on the basis of a health examination. An 11 -year follow-up of 264 male employees in a Swedish pulp and paper company. Scand J Work Environ Health 1988;14:110-17. 
9 Naegele G, Kramer K. Recent developments in the employment and retirement of older workers in Germany. J Aging Soc Policy 2001;13:69-92.

10 Walker A. Managing an ageing workforce. A guide to good practice. Luxembourg: Office for Official Publications of the European Communities, 1999.

11 Ilmarinen J, Louhevaara V. FinnAge-Respect for the aging: action programme to promote health, work ability and well-being of aging workers in 1990-96. Helsinki: Finnish institute of Occupational Health, 1999.

12 Tuomi K, Huuhtanen P, Nykyri E, et al. Promotion of work ability, the quality of work and retirement. Occup Med (Lond) 2001;51:318-24.

13 Ilmarinen J, Tuomi K. Work ability index for aging workers. Helsinki: Finnish Institute of Occupational Health, 1993:142-51.
14 De Zwart BC, Frings-Dresen MH, Van Duivenbooden JC. Test-retest reliability of the Work Ability Index questionnaire. Occup Med (Lond) 2002;52:177-81.

15 Nygard CH, Eskelinen L, Suvanto S, et al. Associations between functional capacity and work ability among elderly municipal employees. Scand J Work Environ Health 1991;17(suppl 1):122-7.

16 Taris TW, Schreurs PJG, Schaufeli WB. Construct validity of the Maslach Burnout Inventory-General Survey: a two-sample examination of its factor structure and correlates. Work and Stress 1999:13:223-37.

17 Hunt SM, McKenna SP, McEwen J, et al. A quantitative approach to perceived health status: a validation study. J Epidemiol Community Health 1980;34:281-6.

\section{$\mathrm{ECHO}$}

\section{Smokers lose an old alibi}

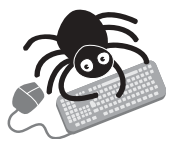

Please visit the Occupational and

Environmental Medicine website [www. occenvmed. com] for a link to the full text of this article. obacco smoke is bad for the environment, according to Italian experimenters who have compared the adverse environmental effects of cigarette smoke and diesel exhaust. The rise of environmental tobacco smoke (ETS) as the largest source of polluting particulates is a powerful argument against smoking to pitch at environmentally aware adolescents, they say.

Regular checks in a closed environment showed that particulates of $10 \mu \mathrm{m}$ diameter $\left(\mathrm{PM}_{10}\right)$ were significantly more abundant from slowly burning cigarettes than from an idling ecodiesel engine (mean (SD) 343 (192) $v 44$ (9) $\mu \mathrm{g} / \mathrm{m}^{3}$ ), after correcting for background amounts. This was also true for smaller particulates- $\mathrm{PM}_{2.5}$ and $\mathrm{PM}_{1}$. Peak $\mathrm{PM}_{10}$ concentration for cigarettes was fifteen times the ambient outdoor concentration whereas the peak for the engine was only about twice as high. $\mathrm{PM}_{10}$ concentration for ETS persisted at $>300 \mu \mathrm{g} / \mathrm{m}^{3}$ up to an hour after the experiment started, way above the EU outdoor limit $\left(40 \mu \mathrm{g} / \mathrm{m}^{3}\right)$.

The tests were performed in a $60 \mathrm{~m}^{3}$ garage in a mountain region with high air quality. Particulate concentrations were measured before each test, and after either three consecutive cigarettes had been left burning for 30 minutes or a 2.01 , 2002 model eco turbo diesel engine running on low sulphur fuel had been left idling for the same time.

The public is worried about particulates in air and increased risk of lung disease. ETS and fossil fuel emissions have similar compositions, but there is concern that air pollution indoors is much higher than that outdoors because of success in cutting vehicle emissions.

A Invernizzi G, et al. Tobacco Control 2004;13:219-221. 